\title{
Spectrophotometric determination of rhodium in intermetallic compounds using flavonoids
}

\author{
Teodoziya Ya. VRUBLEVSKA ${ }^{1}$, Galyna M. MYKHALYNA ${ }^{2}$, Maryana B. URYS $^{2}$ \\ ${ }^{1}$ Ivan Franko National University of Lviv, Faculty of Chemistry, Department of Analytical Chemistry, \\ Kyryla i Mefodiya St. 6, 79005 Lviv, Ukraine \\ ${ }^{2}$ Hetman Petro Sahaydachnyi Army Academy, Faculty of Training Specialists for Engineering Troops \\ and Troops of Nuclear, Chemical and Biological Protection, Department of Chemistry, \\ Gvardiyska St. 32, 79012 Lviv, Ukraine \\ * Corresponding author.Tel.: +380-32-2394048; e-mail: tvryblevska@yahoo.com
}

Received July 5, 2012; accepted December 26, 2012; available on-line July 5, 2013

The paper describes the preparation of new analytical forms of rhodium(III) compounds with flavonoids (morin and quercetin) and its rapid spectrophotometric determination in the intermetallic compounds HoRhIn $_{5}$ and LaRhIn ${ }_{2}$. The concentration ranges of the rhodium ions with morin and quercetin were equal to $0.08-1.50 \mu \mathrm{g} / \mathrm{ml}\left(C_{\min }=0.030 \mu \mathrm{g} / \mathrm{ml}\right)$ and $0.05-2.55 \mu \mathrm{g} / \mathrm{ml}\left(C_{\min }=0.012 \mu \mathrm{g} / \mathrm{ml}\right)$, respectively.

Spectrophotometry / Rhodium(III) / Flavonoids / Intermetallic compounds

\section{Спектрофотометричне визначення родію в інтерметалідах за допомогою флавоноїдів}

\author{
Теодозія Я. ВРУБЛЕВСЬКА ${ }^{*}$, Галина М. МИХАЛИНАㄹ, Мар'яна Б. УРИСЬ² \\ ${ }^{1}$ Львівський наиіональний університет імені Івана Франка, \\ хімічний факультет, кафедра аналітичної хімї, вул. Кирила і Мефодія 6, 79005 Львів, Украӥна \\ ${ }^{2}$ Академія сухопутних військ імені гетьмана Петра Сагайдачного, факультет підготовки \\ спеціалістів інженерних військ та військ радіаційного, хімічного та біологічного захисту, \\ кафедра хімії, вул. Гвардійська 32, 79012 Львів, Украӥна \\ * Контактна особа. Тел.: +380-32-2394048; e-mail: tvryblevska@yahoo.com
}

Робота присвячена застосуванню нових аналітичних форм сполук родію(III) 3 флавоноїдами (морином та кверцетином) для його експресного спектрофотометричного визначення у сплавах HoRhIn $_{5}$ Ta LaRhIn . Межі визначення концентрацій для іонів родію 3 морином та кверцетином становить 0.08-1.50 мкг/мл $\left(C_{\min }=0.030\right.$ мкг/мл $), 0.05-2.55$ мкг/мл $\left(C_{\min }=0.012\right.$ мкг/мл $)$, відповідно.

Спектрофотометрія / Родій(III) / Флавоноїди / Інтерметаліди

Вступ

Родій широко застосовують у різних галузях промисловості: ювелірній для надання виробам особливого блиску і краси, хімічній, де він використовується як каталізатор, скляній - для виготовлення лабораторного хімічного посуду 3 високою хімічною і термічною стійкістю, у техніці, медицині та ін. Родій розсіяний в земній корі і власних мінералів не має, а його одержання із складних об'єктів, які містять й інші подібні за властивостями платиноїди, знижує можливості його використання [1-3]. Тому аналітична хімія родію вимагає розробки нових методів його 
надійного визначення у широких концентраційних межах.

Одним із поширених методів визначення родію $\epsilon$ спектрофотометрія, головними перевагами якої $\epsilon$ простота, доступність та експресність аналізу [4-6]. Більшість спектрофотометричних методик, описаних у літературі, 3 використанням як органічних, так і неорганічних реагентів, мають певні обмеження або по чутливості, або по селективності i часто вимагають складної пробопідготовки [7-10]. Тому пошук нових, доступних, безпечних реагентів, зокрема природного походження, для визначення платиноїдів та детальне визначення механізмів їхньої взаємодії $є$ актуальним.

Як чутливі та достатньо селективні аналітичні реагенти зарекомендували себе флавоноїди морин (Мор) та кверцетин (Кв), які є поширеними представниками великого класу природних поліфенольних сполук та використовуються для визначення багатьох іонів металів [11-16]. Нами попередньо встановлено утворення нових сполук морину та кверцетину з іонами Rh(III) та показано можливість їхнього ефективного застосування при кількісному визначенні іонів цього металу у складних об'єктах [16-18]. Оптимальні умови утворення вказаних сполук та деякі їхні спектрофотометричні характеристики наведені у Табл. 1. Величина аналітичного сигналу спектрофотометричного визначення родію(III) 3 морином та кверцетином лінійно залежить від концентрації іону металу в розчині. Метрологічні характеристики розроблених методик наведено в Табл. 2.
Як видно із даних Табл. 2, розроблені методики спектрофотометричного визначення родію(III) 3 використанням Мор та Кв, характеризуються високою чутливістю та широким концентраційним інтервалом визначуваного компонента. Тому нами вперше застосовано морин та кверцетин для визначення родію в інтерметалідах складу HoRhIn 5 та LaRhIn 2 .

\section{Методика експерименту}

Водні розчини реагентів готували на дистиляті. Для покращення розчинності кверцетину застосовували 96\% етанол. Усі хімічні реактиви, які використовували для досліджень, були аналітично чисті (“хч” чи “ч.д.а.”).

Вихідний стандартний хлоридний розчин $\mathrm{Rh}(\mathrm{III})$ одержували шляхом спікання металічного родію $(99.99 \%)$ масою $0.01-0.05 \Gamma$ iз окиснювальною сумішшю $\left(\mathrm{NaOH}, \mathrm{NaNO}_{3}, \mathrm{Na}_{2} \mathrm{O}_{2}\right)$ у скловуглецевому тиглі. Сплавляння проводили впродовж 1 год у муфельній печі, поступово підвищуючи температуру до $700^{\circ} \mathrm{C}$. Отриманий сплав розчиняли у $3 \mathrm{M}$ хлоридній кислоті при кип'ятінні на піщаній бані до появи червонорожевого забарвлення, охолоджували. Залишки скловуглецю, внесеного при розчиненні, відфільтровували, а одержаний розчин кількісно переносили в мірну колбу місткістю 100.0 мл, доводячи до риски розчином хлоридної кислоти 3 концентрацією 3.0 M [16]. Робочі розчини Rh(III) готували розведенням аліквоти вихідного стандартного розчину $3 \mathrm{M}$ розчином $\mathrm{HCl}$.

Таблиця 1 Оптимальні умови фотометрування та деякі спектрофотометричні характеристики сполук Rh(III) 3 морином та кверцетином.

\begin{tabular}{c|c|c|c|c|c}
\hline Сполука & $\lambda$, нм & $\mathrm{pH}_{\text {опт }}$ & $\begin{array}{c}\varepsilon_{\lambda} \cdot 10^{-4}, \\
\text { л·моль }{ }^{-1} \cdot \mathrm{cm}^{-1}\end{array}$ & $\begin{array}{c}\text { Надлишок } \\
\text { реагенту }\end{array}$ & $\begin{array}{c}\text { Час нагрівання, } \\
\text { хв }\end{array}$ \\
\hline Rh(III)-Мор & 305 & 8.0 & 4.1 & 8-кратний & 20 \\
Rh(III)-Кв & 303 & 4.2 & 3-кратний & 15 \\
\hline
\end{tabular}

Таблиця 2 Метрологічні характеристики спектрофотометричного визначення $\mathrm{Rh}(\mathrm{III}) 3$ флавоноїдами, $\mathrm{n}=5, \mathrm{P}=0.95$.

\begin{tabular}{|c|c|c|}
\hline Реагент & Mop & Кв \\
\hline $\mathrm{C}_{\text {pear. }} \cdot 10^{5}, \mathrm{M}$ & 3.0 & 3.0 \\
\hline$\lambda, \mathrm{HM}$ & $305(315)$ & $303(315)$ \\
\hline Межі лінійності, мкг· мл ${ }^{-1}$ & $0.08-1.50$ & $0.05-2.55$ \\
\hline Рівняння графіка, $\mathrm{C}_{\mathrm{Rh}}$, мкг·мл ${ }^{-1}$ & $\Delta \mathrm{A}_{315}=-0.026+1.049 \times \mathrm{C}_{\mathrm{Rh}}$ & $\Delta \mathrm{A}_{305}=0.062+0.409 \times \mathrm{C}_{\mathrm{Rh}}$ \\
\hline $\mathrm{C}_{\mathrm{H}}, \mathrm{MKг \cdot \textrm {M } ^ { - 1 }}$ & 0.086 & 0.035 \\
\hline $\mathrm{C}_{\min }$, мкг·мл ${ }^{-1}$ & 0.029 & 0.012 \\
\hline $\mathrm{R}$ & 0.9991 & 0.9997 \\
\hline
\end{tabular}


Ідентифікацію отриманого та робочого розчинів проводили спектрофотометрично: порівнянням електронних спектрів світлопоглинання одержаних розчинів із літературними даними [19], які підтверджують домінування родію у розчинах у вигляді комплексних іонів $\left[\mathrm{RhCl}_{6}\right]^{3-}$.

Стандартизацію отриманого розчину родію(III) проводили титриметричним методом Сирокомського та Прошенкової, за здатністю $\mathrm{Rh}(\mathrm{III})$ окиснюватися натрій бісмутатом до $\mathrm{Rh}(\mathrm{V})$ у сульфатнокислих розчинах [20]. За даними титрування розраховували вміст $\mathrm{Rh}(\mathrm{III})$ у розчині.

Вихідні стандартні розчини морину та кверцетину 3 концентрацією $\sim 10^{-3} \mathrm{M}$ готували розчиненням точної наважки реактивів фірм "LOBA CHEMIE" та "CHEMAPOL" кваліфікації “ч.д.а." в 96\%-ному етанолі. Чистоту та точну концентрацію флавоноїдів перевіряли методом рідинної хроматографії згідно 3 методикою, адаптованою до кожного флавоноїда. Ідентифікацію проводили спектрофотометрично, порівнюючи ЕСП одержаних розчинів 3 літературними даними [21-23]. Робочі розчини флавоноїдів готували розведенням певних аліквот їхніх стандартних розчинів у $96 \%$ етиловому спирті.

Вимірювання світлопоглинання проводили на фотоколориметрі КФК-2 - УХЛ 4.2 (Україна) та скануючих спектрофотометрах CARY.WIN UV-VIS-50 (Varian, CШA) i SPECORD M-40 (Carl Zeiss Jena, Німеччина) в кюветах 1=1-3 см. Величину $\mathrm{pH}$ вимірювали $\mathrm{pH}$-метром $\mathrm{pH}-150 \mathrm{M}$ (РУП "Гомельский завод измерительных приборов”, Білорусь) 3 аргентумхлоридним електродом порівняння. Необхідне значення кислотності середовища створювали додаванням розчинів $\mathrm{HCl}$ та $\mathrm{NaOH}$.

\section{Результати і обговорення}

Згідно $з$ експериментальними дослідженнями та результатами вивчення селективності спектрофотометричного визначення родію(III) 3 флавоноїдами [16] показано, що присутність іонів рідкісноземельних металів (Ho(III), La(III)) та In(III), які $\epsilon$ компонентами металевих сплавів, утруднюють аналіз вже при співвідношеннях $\mathrm{C}_{\mathrm{Rh}(\mathrm{III})}: \mathrm{C}_{\mathrm{M}}=1: \leq 0.5$, що пов'язано 3 утворенням забарвлених комплексів стійкіших від сполук аналіту 3 Мор та Кв. Тому нами проведено ряд досліджень стосовно усунення впливу сторонніх компонентів за допомогою маскуючих аніонів, таких як ЕДТА, фторид-, цитрат-, тартрат-іонів.

\section{Методика розчинення інтерметалідів}

Наважку сплаву масою $~ 0.02-0.03$ г розчиняли у 10-20 мл суміші концентрованої хлоридної та нітратної кислот (10:1). Одержану суміш кип'ятили на піщаній бані упродовж 1-2 год. Отриманий розчин кількісно переносили в мірну колбу ємністю 50.0 мл та доводили до мітки $6 \mathrm{M}$ $\mathrm{HCl}$. Для аналізу відбирали аліквоти розчинів об'ємом 0.5-2.0 мл та визначали родій згідно 3 методикою, описаною нижче.

\section{Визначення родію у інтерметалідах}

У мірну колбу місткістю 25 мл вносять аліквоту досліджуваного розчину інтерметаліду, 2.5 мл $1 \mathrm{M}$ розчину натрій хлориду (2.5 мл 96\% етанолу при використанні кверцетину), додають 2.0 мл $3,8 \cdot 10^{-4} \mathrm{M}$ розчину морину чи кверцетину. Встановлюють кислотність середовища отриманого розчину $\mathrm{pH}=8.0$ на $\mathrm{pH}$-метрі за допомогою розчинів $\mathrm{HCl}$ та $\mathrm{NaOH}$ та проводять вимірювання інтенсивності світлопоглинання досліджуваного розчину після нагрівання впродовж 20 хв на киплячій водяній бані та охолодження при $\lambda=315$ нм $3 \quad 1=3 \mathrm{~cm}$ відносно “холостої проби”, підготовка якої проводилася аналогічно. Концентрацію родію(III) знаходять за попередньо побудованим градуйованим графіком або способом порівняння чи добавок.

Результати визначення родію у інтерметалідах $\mathrm{HoRhIn}_{5}$ та LaRhIn 2 представлені у Табл. 3 та 4.

Як показують дані таблиць, за допомогою різних надлишків ЕДТА, Tart ${ }^{2-}, \mathrm{Cit}^{3-}$ вдалося усунути заважаючий вплив рідкісноземельних елементів та індію при визначенні родію у сплавах. При використанні фторид-іонів повністю замаскувати вплив супутніх іонів не вдалося, проте його можна використати для приготування маскуючих сумішей, за допомогою яких можна зменшити похибку визначення. Одержані результати визначення вмісту родію в інтерметалідах складу HoRhIn 5 та $\mathrm{LaRhIn}_{2}$ спектрофотометричним методом добре узгоджуються 3 його вмістом, розрахованим за атомними відсотками.

\section{Висновки}

На основі проведених нами комплексних досліджень взаємодії іонів родію(III) 3 морином та кверцетином розроблено прості та експресні методики спектрофотометричного визначення $\mathrm{Rh}(\mathrm{III})$ за допомогою даних флавоноїдів у металевих трикомпонентних сплавах HoRhIn 5 та $\mathrm{LaRhIn}_{2}$. Вивчено вплив сторонніх та супутніх іонів на утворення досліджуваних сполук та показано можливість застосування маскуючих агентів для усунення впливу іонів гольмію(III), індію(III) i лантану(III), які присутні у аналізованих інтерметалідах. Значення $\mathrm{S}_{\mathrm{r}}(\sim 2,0 \%)$ не перевищує похибку спектрофотометричних методів аналізу. 
T.Ya. Vrublevska et al., Spectrophotometric determination of rhodium in intermetallic compounds ...

Таблиця 3 Результати спектрофотометричного визначення вмісту родію у сплаві $\mathrm{HoRhIn}_{5} 3$ флавоноїдами, $\mathrm{pH}=8.0,1=1-3 \mathrm{~cm}, \lambda=315$ нм, $\mathrm{n}=3, \mathrm{P}=0.95$.

\begin{tabular}{|c|c|c|c|c|c|}
\hline Реагент & $\begin{array}{c}\text { Маскуючий } \\
\text { агент }\end{array}$ & $\mathrm{C}_{\mathrm{Rh}}: \mathrm{C}_{\text {маск }}$ & $\omega_{\mathrm{Rh}}^{\text {posp }}, \%$ & $\bar{\omega}_{R h}^{n p} \pm \frac{S \cdot t_{\alpha}}{\sqrt{n}}, \%$ & $S_{\mathrm{r}}, \%$ \\
\hline морин & $\begin{array}{c}\text { ЕДТА } \\
\text { Tartt }^{2-} \\
\mathrm{Cit}^{3-} \\
\text { ЕДТА }+\mathrm{F}^{-}\end{array}$ & $\begin{array}{c}1: 2 \\
1: 3 \\
1: 20 \\
1: 2 \text { (ЕДТА }), 1: 20\left(\mathrm{~F}^{-}\right)\end{array}$ & \multirow{2}{*}{12.22} & $\begin{array}{l}12.05 \pm 0.37 \\
11.56 \pm 0.84 \\
11.92 \pm 0.45 \\
12.15 \pm 0.40\end{array}$ & $\begin{array}{l}1.26 \\
2.93 \\
1.51 \\
1.32\end{array}$ \\
\hline кверцетин & $\begin{array}{c}\text { ЕДТА } \\
\text { Tart }^{2-} \\
\mathrm{Cit}^{3-} \\
\text { ЕДТА }+\mathrm{F}^{-} \\
\end{array}$ & $\begin{array}{c}1: 2 \\
1: 3 \\
1: 50 \\
1: 2(\text { ЕДТА }), 1: 20\left(\mathrm{~F}^{-}\right)\end{array}$ & & $\begin{array}{l}12.06 \pm 0.57 \\
11.82 \pm 0.55 \\
12.28 \pm 0.44 \\
12.11 \pm 0.35\end{array}$ & $\begin{array}{l}1.91 \\
1.87 \\
1.44 \\
1.16 \\
\end{array}$ \\
\hline
\end{tabular}

Таблиця 4 Результати спектрофотометричного визначення вмісту родію у сплаві $\operatorname{LaRhIn}_{2} 3$ флавоноїдами, $\mathrm{pH}=8.0,1=1-3 \mathrm{~cm}, \lambda=315 \mathrm{нм}, \mathrm{n}=3, \mathrm{P}=0.95$.

\begin{tabular}{|c|c|c|c|c|c|}
\hline Реагент & $\begin{array}{c}\text { Маскуючий } \\
\text { агент }\end{array}$ & $\mathrm{C}_{\mathrm{Rh}}: \mathrm{C}_{\text {Mack }}$ & $\omega_{\mathrm{Rh}}{ }^{\text {розр }}, \%$ & $\bar{\omega}_{R h}^{n p} \pm \frac{S \cdot t_{\alpha}}{\sqrt{n}}, \%$ & $S_{\mathrm{r}}, \%$ \\
\hline морин & $\begin{array}{c}\text { ЕДТА } \\
\text { Tart }^{2-} \\
\mathrm{Cit}^{3-} \\
\text { ЕДТА }+\mathrm{F}^{-}\end{array}$ & $\begin{array}{c}1: 2 \\
1: 3 \\
1: 20 \\
1: 2 \text { (ЕДТА }), 1: 20\left(\mathrm{~F}^{-}\right)\end{array}$ & \multirow{2}{*}{21.83} & $\begin{array}{l}21.52 \pm 0.46 \\
21.68 \pm 0.54 \\
21.11 \pm 1.01 \\
21.75 \pm 0.43\end{array}$ & $\begin{array}{l}0.86 \\
1.00 \\
1.93 \\
0.80\end{array}$ \\
\hline кверцетин & $\begin{array}{c}\text { ЕДТА } \\
\text { Tart }^{2-} \\
\mathrm{Cit}^{3-} \\
\text { ЕДТА }+\mathrm{F}^{-}\end{array}$ & $\begin{array}{c}1: 2 \\
1: 3 \\
1: 50 \\
1: 2 \text { (ЕДТА }), 1: 20\left(\mathrm{~F}^{-}\right)\end{array}$ & & $\begin{array}{l}21.61 \pm 0.50 \\
21.27 \pm 1.09 \\
22.07 \pm 0.66 \\
21.72 \pm 0.97\end{array}$ & $\begin{array}{l}0.92 \\
2.07 \\
1.21 \\
1.80\end{array}$ \\
\hline
\end{tabular}

\section{Подяка}

Автори висловлюють подяку доц. Зарембі В.І. за представлені зразки інтерметалідів для проведення досліджень.

\section{Література}

[1] С.И. Гинзбург, Н.А. Езерская, И.В. Прокофьева, Н.В. Федоренко, В.И. Шленская, Н.К. Бельский, Аналитическая химия платиновых металлов, Наука, Москва, 1972, 616 с.

[2] С. Ливингстон, Химия рутения, родия, палладия, осмия, иридия, платины, Мир, Москва, 1978, 366 с.

[3] Ю.А. Золотов, Г.В. Варшал, В.М. Иванов, Аналитическая химия металлов платиновой группь:: Сборник обзорных статей, Едиториал УРСС, Москва, 2003, 592 с.

[4] О.А. Ефременко, В.И. Шленская, И.П. Алимарин, Изв. АН СССР, Сер. хим. 4 (1969) 740-745.
[5] K. Swamunathan, G.H. Garris, J. Amer. Chem. Soc. 83 (1966) 4411-4414.

[6] Т.М. Буслаева, Д.С. Умрейко, Г.Г. Новицкий, Химия и спектроскопия галогенидов платиновых металлов, Университетское, Минск, 1990, 279 с.

[7] J.S. Forrester, G.H. Ayres, J. Phys. Chem. 63 (1959) 1979-1981.

[8] Y-L. Lin, E. Turos, J. Organomet. Chem. 630 (2001) 57-66.

[9] Е.М. Басова, В.М. Иванов, Т.А. Большова, Н.А. Бабкова, Журн. аналит. хим. 45 (1990) 671-677.

[10] C. Bosch Ojeda, F. Sánchez Rojas, Talanta 67 (2005) 1-19.

[11] П.І. Середа, Н.П. Максютіна, Л.Л. Давтян, Фармакогнозія. Лікарська рослинна сировина та фітозасоби, Нова Книга, Вінниця, 2006, $352 \mathrm{c}$.

[12] К. Бургер, Органические реагенты в неорганическом анализе, Мир, Москва, 1975, $262 \mathrm{c}$.

[13] А.Т. Пилипенко, Т.А. Васильчук, А.И. Волкова, Журн. аналит. хим. 38 (1983) 855-861. 
T.Ya. Vrublevska et al., Spectrophotometric determination of rhodium in intermetallic compounds ...

[14] А.Б. Бланк, Л.Э. Беленко, Журн. аналит. хим. 33 (1978) 65-69.

[15] А.П. Головина, В.Г. Типцова, Журн. аналит. хим. 17 (1962) 524-525.

[16] Г.М. Михалина, Спектрофотометрія сполук флавоноїдів морину, кверцетину та лютеоліну з деякими платиноїдами. Дис. канд. хім. наук: 02.00.02. Дніпропетровськ, 2012. 207 c.

[17] Г.М. Михалина, Т.Я. Врублевська, Вопр. хим. хим. технол. 5 (2010) 80-83.

[18] Г. Михалина, Т. Врублевська, М. Урись, Ю. Луцишин, Materials Science (Фізикохімічна механіка матеріалів) 47(3) (2011) 125-128.
[19] И.П. Алимарин, В.И. Шленская, А.А. Бирюков, О.А. Ефременко, В.П. Хвостова, Журн. аналит. хим. 25 (1970) 1965-1977.

[20] В.С. Сырокомский, Н.Н. Прошенкова, Журн. аналит. хим. 2 (1947) 247-252.

[21] M. Balcerzak, M. Kopacz, A. Kosiorek, E. Święcicka, S. Kuś, Anal. Sci. 20 (2004) 1333-1337.

[22] О.М. Гриценко, Л.С. Дегтярьов, Л.Б. Пилипчук, Фармацевтичний журн. 2 (1999) 34-38.

[23] А.Т Пилипенко, Т.А. Васильчук, А.И. Волкова, Журн. аналит. хим. 39 (1984) 581-587. 